\title{
Learning with Mobiles in the Digital Age
}

\author{
JOHN TRAXLER
}

\begin{abstract}
Personal mobile devices are central to the current digital age, and will soon be pervasive and ubiquitous, and unremarkable in most of the world's societies and cultures. They are central to the educational futures for the digital age, to both in theory and practice. They are, however, not straightforward. Whilst the relationships of these technologies to formal education and its professions and institutions, conceptualised as 'mobile learning', seemed straightforward, it has also become increasingly marginal and irrelevant whilst the relationship between mobile devices and society outside formal education is increasingly problematising the nature, role and purpose of both education and learning. This article explores this tension; it characterises and conceptualises it in terms of competing paradigms.
\end{abstract}

Keywords: mobile learning, paradigm, learning with mobiles, innovation, paradigm.

\section{INTRODUCTION}

There is a fundamental paradox or tension that we hope to describe, discuss and analyse in exploring the role of mobile technologies for learning in the digital age. It is a paradox or tension between what we describe as two paradigms, and these represent a convenient lens to structure our chapter. Sticking to a broadly Kuhnian definition of paradigm (Kuhn, 1970) allows us to identify not some underlying defining axioms but also the chronological development, the geographical distribution, the evolving research agenda, the external environment, the practical and practitioner impact, and the emerging fractures and discrepancies at the periphery of each paradigm. So, we are talking about axioms, communities, norms and priorities, meaning those axioms, those apparently self-evident truths, to which the community subscribes, that form the basis for membership of that community and the basis for its activities, for writing the exam questions, the textbooks, the research proposals and for defining the frontiers of knowledge. This depiction clearly puts paradigms in an explicitly social context, not as abstract doctrines but as shared beliefs and missions that drive actions. There is also an historical or narrative context, showing how paradigms develop and interact, and specifically how one paradigm often evolves out of discontent and dissatisfaction with an earlier one, a paradigm shift in fact. We portray this shift in terms of an historical shift away from the early definitions, perhaps "any educational provision where the sole or dominant 
technologies are handheld or palmtop devices" (Traxler, 2005) to a more robust and all-embracing definition, something like, "acquiring the knowledge, attitudes, skills and processes appropriate to or aligned to societies characterised, perhaps defined, by individual and collective connectedness and mobility."

One paradigm was situated amongst academics, universities and countries in a handful of mobile learning 'hotspots' in parts of the world's developed regions, a project intended to enhance and extend institutional e-learning (Traxler, 2008a), to deliver on the promise of learning 'anywhere, anytime', and even 'just-in-time, just-for-me' (Hlodan, 2010; Shih, 2007). This paradigm dates back about two decades and is the classical 'mobile learning' paradigm as usually understood by academics. It was documented in its early years in a variety of publications and presentations. A search of Google and Google Scholar using 'mobile learning' as search terms will reveal the extent of the community, uncover its axioms, pick out cognate concepts (such as 'seamless learning', 'connected learning' and '1:1 learning and some synonyms, noticeably 'm-learning', even 'nomadic learning' - Chan et al., 2006), and give some clues to the foundational texts and the years of its heyday. A reading of these publications and presentations and the projects that underpin them does, however, reveal a narrow bandwidth in terms of methods, theories, formats, settings, objectives and findings, and could indicate a paradigm that was stable or perhaps stagnant.
The other paradigm, more recent and less coherent, is driven by the ways in which increasingly pervasive, ubiquitous personal mobile digital technologies were transforming the ways in which people and communities could generate, discuss, transform, share, discard and store ideas, opinions, identities, images and information, and, in effect, become each other's teachers.

Neither of these springs into existence from nowhere. They are each a product of some wider and earlier culture, context and conditions, specifically of economic, political and ideological conditions; these are, however, all local, different and specific. In any given comparison of the paradigms, we see a comparison between one rooted in institutional and formal learning, the other in informal social practices but we also see the impact of different host cultures, including national, generational, ethnic and virtual. So, in some respects we are claiming that what is actually experienced and observed are both local instances of the two generic paradigms. Of course, neither of these paradigms are necessarily unconditionally benign or ethically straightforward; they each serve different interests, they have different relationships to established ideas of education, its institutions, its professions and its purpose, the former to reform and improve, the latter the transform and subvert.

To look at this in another way, these two paradigms represent two different versions of what we might call the knowledge economy, meaning those processes by which knowledge is produced, distributed, 
traded and discarded. The first is a centralised and regulated industrial system based within the formal institutions of the education system and devoted to the mass production of graduates (and in this respect, mobile learning is just part of the ongoing industrialisation of education necessitated by the massification of education (Traxler, 2010a). The second is a decentralised cottage industry where individuals barter or donate the knowledge they have produced, assembled or collected amongst themselves. This is an imperfect metaphor. Learning is not a zero-sum game, the teacher losing the knowledge that the learner gains, nor in many cultures is learning merely about knowledge transfer.

Academia was ever tribes and territories (Becher \& Trowler, 2001) and may be these are more powerful and durable than the explicit or tacit dogma of our two paradigms. An exploration of citations and conference attendance might objectively confirm the sense that such tribes and territories were the self-referential social basis for the paradigms we describe.

This article sets out the breadth of learning with mobiles, to provide the basic chronology, conscious of the various geographical and cultural inflections, to set out the fundamentals as articulated by activists and advocates, and to move beyond overly simplistic depictions. The author approaches learning and mobiles within a broadly historical framework.

This is important since learning and mobiles intersected with the work of national ministries and international agencies as an apparent no-brainer for delivering their humanitarian, economic and social missions. It is also important in the light of perceptions outside academia that mobiles are now universal; education is widely understood so researchers and research findings are no longer needed. There are however often very mixed signals: ministries will promote the use of mobiles in schools, colleges, and universities, teachers and lecturers will affronted by their mis-use and directors and headteachers will ban or confiscate them.

We start by looking at the emergence of mobile learning as a research activity in different academic communities, the definitions and theories, and the defining projects and ideas, specifically from the aspirations, challenges and constraints of elearning. We then explore how these early pilots, projects and programmes were given various conceptual frameworks. These progressively led to peer-reviewed research journals, annual international conferences, professional associations, research studentships and practitioner textbooks - all indicators of an expanding paradigm, albeit the younger sibling of an established one, e-learning.

The rhetoric and funding that underpinned this first phase were threatened by the changed global political and economic climates of the late 2000s. They were also challenged by a shift and increase in the mass of activity and output to USA with its emphasis on training, drill and business models (coincident with the arrival of the iPhone) and away from the earlier curiosity-driven research of Western Europe and the socially-motivated interventions 
of Southern Africa. Even in these original incubators of mobile learning, regional differences were apparent. The emphasis in Southern Africa was on 'service delivery', meaning whatever initiatives helped under-resourced (higher) education systems (Brown, 2003). Several South African universities led the way, using SMS to maintain contact and continuity with dispersed and impoverished student populations, retrieving library books, fees and assessments, and providing guidance (Brown $\&$ Mbati, 2015). In North America, the focus was on games and drill (Wagner, 2005; Quinn, 2012) whilst in Asia Pacific mobile learning interlocked with initiatives for seamless and one-to-one learning in the classroom. In Western Europe, the focus was often informal learning, from basic literacy to higher education, often as a vehicle for exploring models of cognition. By contrast, vast swathes of South America, the Middle East, China, Russia and much of Sub-Saharan Africa were without any projects, pilots or programmes affiliated to the paradigm we are describing.

At the same time, we did see the relentless transformation of mobile technology from scarce, obscure, fragile, expensive, and impersonal to universal, robust, easy, obvious, cheap, and variously described as embodied or prosthetic. This marks the emergence of the second paradigm, almost an Arab Spring of education (Traxler, 2015), where mobile technologies in the hands of individuals and communities can bypass or marginalise the established institutions and professions of educational authority and their control over learning.
The author uses this set of relationships as the lens for a critical account of mobiles and education, an account that starts at the turn of the century when developers, researchers and activists had already seen the potential of mobile technologies and were beginning to come together to report their early projects and proposals.

\section{The Narrative and Historical Context}

The idea of learning with mobile devices in its current form is nearly two decades old. The first research workshop was held in 2002 in Birmingham, UK, but obviously the projects being reported there already had a year or two of progress behind them and a year of development, bidding and funding before that (Naismith \& Corlett, 2006; Naismith et al., 2005).

In the earlier half of this first decade, sophisticated mobile technology was scarce, fragile, expensive and difficult, and was the prerogative of institutions, and the global economy seemed buoyant and robust. This meant that mobile learning was positioned at the vanguard of e-learning research (Georgiev, Georgieva, \& Smrikarov, 2004; Holmes \& Gardner, 2006, 35-42) and necessarily bought into the rhetoric, vocabulary, mechanics and funding of innovation (Rogers, 2010), leading to an ecosystem of projects and pilots, and ideas about early adopters, opinion-formers and critical mass within institutional settings. It grew out of the aspirations and frustrations of e-learning and built on the same foundational disciplines of computing, education and psychology 
but produced evidence and output that had little to say outside the realms of small-scale, fixed-term, subsidised projects and of pilots run by enthusiasts with stable consistent hardware platforms.

There is a different and parallel argument, a more critical one, that in positioning mobile learning in the vanguard of higher education e-learning we have to recognise analyses that portray it as the industrialisation of higher education (Peters \& Keegan, 1994). The political agenda of inclusion, opportunity and participation in education, that accounted for the phenomenon of massification (Teichler, 1998), without the necessarily disproportionate investment in staff and resources, implied an educational mass production system that necessitated computers. Was mobile learning in this analysis merely the next step, a kind of flexible manufacturing system (Eaton \& Schmitt, 1994) that could supersede the educational production line of learning objects, networked computers and learning management systems (Traxler, 2010a)? Just-in-time is a term used to refer to learning and manufacturing! Put in this kind of context, the increasing privatisation of higher education might have meant many mobile learning projects were merely fodder for competitive, corporate advertising and recruitment and sources of research revenue, and that one consequence of these factors was that such projects were relegated to the periphery of mainstream credit-bearing courses.

The first decade of 'mobile learning' was in retrospect the apotheosis of the e-learning of the 1990s, certainly in Western Europe (Kukulska-Hulme et al., 2011) and perhaps too in outliers in Asia Pacific. The 'mobile learning' community persuasively demonstrated that mobile devices could deliver learning to people, communities and countries where earlier educational interventions would have been too expensive, difficult or demanding. These countries, communities and individuals might have been geographically remote, sparsely-distributed, sociallyisolated or physiologically different. The community also demonstrated that mobile devices could extend, enhance, enrich, challenge and disrupt existing ideas and assumptions about learning. The community also challenged existing conceptualisations and theories of learning itself and lastly showed that mobiles could raise motivation for learning especially amongst disenfranchised and disengaged learners. Through this time, definitions were the subject of considerable debate. The early and obvious definitions focused on mobile technologies as the defining characteristic but later and more thoughtful definitions focused on the mobility of the learner and of the learning, specifically on its capacity to cross contexts, from, for example home to school, formal to informal and field-trip to lecture theatre. Throughout this first decade the projects revolved however in practice around the mobile technologies, and around implementations and deployment that were relatively expensive, fragile, formal, small-scale, short-term, institutional and subsidised, taking place in a benign albeit deceptive and deteriorating, global economic climate. Much of the budget for the earliest projects was consumed getting the system to work and getting its components to inter-operate; the pedagogic element was 
secondary and evaluation was necessarily marginal; budgets and schedules were eroded or over-shot. Obviously as technologies and expertise matured these problems faded but our point is that, this became irrelevant as mobile technologies became personal, universal and social rather than institutional and academic.

The theoretical foundations were those of Engeström and Laurillard. Their conceptual frameworks featured in probably the majority of 'mobile learning' journal papers, at various level of abstraction and sophistication. This was driven by a pre-occupation for using small-scale interventions to explore theoretical ideas and was accompanied by a shift in focus and definition towards 'learning across contexts' (Winters, 2006). These and other definitions at the time assumed the content, composition and control of learning were largely unchanged but were somehow in motion, that 'mobile learning' was the established conception of 'learning' but made mobile, a subset of an otherwise unchanged conception. The axioms of the second paradigm (Traxler, 2016; Traxler, 2010b) would be profoundly at odds with this specific point, seeing societal mobility and connection as changing the epistemological foundations of learning and thus of learning itself (Büscher \& Urry, 2009).

By the end of this first decade, mobile technology had become universal, robust, cheap, diverse and easy, and suddenly the global economy was visibly fragile and weak. For institutions, change, if it happened, was forced outside-in, from the expectations of the societies that hosted these institutions rather than their thought leaders, no longer promoted top-down. Mobile technology became so familiar that policy makers and practitioners could be excused for thinking that learning with mobiles was now common-sense, and that theories, research and researchers were no longer necessary. The foundational disciplines should have now included sociology rather than psychology, but did not, and recognised that mobile technologies challenge, disrupt and by-pass the processes and institutions of formal learning and knowing rather than merely enhancing and reinforcing them.

\section{The Mobile Learning PARADIGM}

In the decade after 2001, mobile learning matured and consolidated, and soon had a peer-reviewed academic journal, the International Journal of Mobile and Blended Learning and a professional body, the International Association for Mobile Learning. It also had a large on-line community and several prestigious annual international conferences such as mLearn. There were key emerging working texts (Kukulska-Hulme \& Traxler, 2005; Ally, 2009; Metcalf, 2006; JISC, 2005); there were emerging guidelines for practitioners (for example, Vavoula et al., 2004). Mobile learning identified significant issues (for example, Sharples, 2006, defining the big issues), a growing portfolio of projects (Fröhberg, Göth, \& Schwabe, 2009), a more sharply-defined research agenda (ArnedilloSánchez, Sharples, \& Vavoula, 2007), and an awareness of ethical guidelines and frameworks (Traxler, 2008b) - in essence, all the constituents of a Kuhnian paradigm. 
As it reached its mature form, 'mobile learning' seemed, through the obscuring fog of reality on the ground, to have made three or four significant demonstrations of progress and achievement that encapsulated its axioms as a paradigm. These are as follows:

Firstly, the mobile learning research community demonstrated across a variety of contexts that it could enhance, extend and enrich the concept and activity of learning itself, beyond earlier conceptions of learning and specifically of e-learning. This included

- Contingent or agile learning and teaching, where learners could react and respond to their changing environment and experiences, for example with realtime data collection and analysis on geography field trips; where teachers could change their teaching in response to the changing affordances of the environment or the learners, for example using pico-projectors and improvised interactive whiteboards (Traxler \& Griffiths, 2009) or using personal response systems with groups of students (Draper \& Brown, 2004).

- Situated learning, where learning took place in surroundings that made it relevant and meaningful. This included learning about religions whilst visiting temples, mosques, churches and synagogues (Burke, 2010); language learning in language communities (Pfeiffer et al., 2009; Thorton \& Houser, 2005; Comas-Quinn, Mardomingo, \& Valentine, 2009; Kukulska-Hulme, 2009; de Crom \& de Jager, 2005).
- Authentic learning, where meaningful learning tasks were related to immediate learning goals, for example basic literacy or numeracy in work-based learning on the job or learning on placement for junior doctors in surgeries, student vetenarian surgeons in consultations, nursing trainees in the wards and trainee teachers in schools (Smördal \& Gregory, 2003; White et al., 2005; Kneebone \& Brenton, 2005; Kenny et al., 2009).

- Context-aware learning, where learning was shaped by the history, surroundings and environment of the learner, for example learning in botanical gardens, museums, game parks or heritage sites. This was however mostly episodic and isolated. The increased functionality of mainstream retail devices opened up enormous possibilities for developing more intelligence and using more history behind the learner experience (Lonsdale et al., 2004; Brown, 2010; Yau \& Joy, 2009; Traxler \& Kukulska-Hulme, 2015).

- Augmented reality mobile learning, where learning built on local physical context supplemented by an audio or video overlay (Smith, 2008; Jarvis \& Priestnall, 2008).

- Personalised learning, where learning was customised for the preferences and abilities of individual learners or groups of learners (Dale, 2007; KukulskaHulme \& Traxler, 2005).

- Pastoral support and organisational support for students (Riordan \& Traxler, 2005; Corlett \& Sharples, 2004). 
- Game-based learning, became increasingly mobile (Facer et al., 2004; Giles, 2009; Kato et al., 2008; Pulman, 2008).

- Assessment techniques that are aligned to these new affordances (Dearnley, Haigh, \& Fairhall, 2008).

These represented or facilitated a trend to take learning away from the classroom and the lecture theatre, in fact, away from the institution, and supported courses and programmes in practical ways to engage with the world outside the institutions, either exploring that world or preparing students to take their places in it.

Secondly, the mobile learning research community demonstrated that it could take learning to individuals, communities and countries that were previously too remote or sparse, economically, socially or geographically, for other external educational initiatives. This included addressing

- Geographical or spatial distance, for example reaching into deeply rural areas. This became educationally richer as networks drove out greater bandwidth and coverage but was held back by shortage of more modern handsets and support (Motlik, 2008). An example is Janala in Bangladesh (Walsh, Shrestha, \& Hedges, 2011).

- Sparsity, connecting thinly-spread and perhaps nomadic learners to create viable communities of learners; infrastructural or technical barriers, for example, in areas of South Asia or Sub-Saharan Africa, supporting those communities lacking mains electricity, secure clean buildings or land-line connectivity (Traxler \& Leach, 2006).
- Social exclusion, for example, reaching students unskilled in, unfamiliar with and lacking confidence in formal learning, for example the homeless, gypsies, marginal groups, those not-in-education-employment-or-training (NEETs) (Collett \& Stead, 2002; Attewell \& Savill-Smith, 2004), lower socio-cultural groups (Unterfrauner et al, 2010) and township youth (Botha et al., 2008).

- Physiological or cognitive differences, for example supporting learning opportunities for the hearing impaired or providing scheduling support and organisational support for people with dyslexia (Rainger, 2005).

- Dead-time, small bursts of otherwise unused time, such as waiting in lifts, cafes, buses, queues; sometimes used as an example of 'bite-sized' learning; although possibly limited educationally in this formulation, mobile phones will always be carried by learners whereas books or laptops might not be (Levy \& Kennedy, 2005).

- Corporate training, delivering training, especially compliance, to dispersed and peripatetic workforces (Attewell et al., 2010; Gayeski, 2002; Nikoi, 2007).

- This aspect of mobile learning was more pragmatically-driven than theoreticallyinformed, and less well documented since funding prioritised delivery not dissemination.

- For any of these activities but especially those where learning was being extended into communities that were remote, the mobile learning activists did not always recognise that technology, including mo- 
bile digital technology, always had ideology or perhaps pedagogy embedded in it. These technologies projected the pedagogies, and perhaps the epistemologies, of outsiders into communities that of course already had their own learning. There was a risk that mobile technologies delivering learning represented a Trojan horse or a cargo cult (Lindstrom, 1993; Worsley, 1957) that threatened or undermined fragile local learning ecosystems. So, a unifying theme across different aspects of this 'mobile learning' paradigm was the notion that learning was done by educators to learners, for learners, at learners but with very little agency and control, by learners. Heeks (2008) might have characterised this as 'mobile learning1.0' rather than 'mobile learning2.0', done with and by learner rather than at and to learners.

Thirdly, the mobile learning research community has challenged and extended theories of learning (Brown, 2005; Sharples, Taylor, \& Vavoula, 2007) (for example, Laurillard, 2007 in extensions to her own 'conversational framework') and engaged with wider theories (for example, Engeström, with his activity theory (Engeström, 2001) and latterly wildfire learning (Engeström, 2009), and for example, Beddall-Hill and Raper (2010) engaging with actor network theory), with the increasing addition of the FRAME concept (Koole \& Ally, 2006) in the less theoretical papers. This took place across both formal learning, including the university sector and the schools sector, and informal learning, including adult learners and visitors at art galleries and heritage sites.
The final, fourth, claim was often made, often in funding proposals, that learning with mobile devices increased learners' enthusiasm and motivation (there was considerable impressionistic soft - sometimes characterised as fuffy evidence for this claim) and consequently improved retention and progression, key educational performance indicators (a very dubious proposition).

The projects grew out of the ideas and lexicon of innovation, for example, phrases like 'early adopters', 'critical mass' and 'change agents', that were popular at the time; they were often funded as developmental projects, intended to become established within institutions by a process of downward and outward diffusion, by a trickle-down, and intended to become embedded and mainstreamed. This may or may not have happened but generally, the finances and culture were against them. The finances were against them because the innovation looked like an extra cost for an un-quantified benefit with what some journalists had called as mentioned earlier, only fluffy evidence and the culture was against them because innovators were driven by very different ideals and objectives compared to mainstream lecturers, their managers and their quality assurance regimes. The evidence was not always convincing or apparent but the extra costs were. Therefore, most mobile learning projects from this era never got beyond a pilot phase and a research paper, and then the researchers moved on from one innovation to the next innovation, in a parallel universe of research funding. In 
any case, the funding agencies moved on from the mind-set of innovation, preferring to address change at a more systemic and institutional level, leaving mobile learning in a limbo.

These projects were usually funded across a year maybe two, with a handful of staff, the enthusiasts, advocates and visionaries, alongside rather than inside the core staff and assessed curriculum; these features militated against an embedded sustainable future. Hardware, that is the necessary mobiles or earlier PDAs, was usually built into the budget. It guaranteed a uniform and consistent platform, removed a confounding variable and reduced technical problems. It also limited the size of any sample and produced no exit strategy. It had no sustainability in terms of finance or culture. Because of risk and finance, research early in the lifecycle of any paradigm often takes place within individual $\mathrm{PhD}$ programmes, before moving onto externally-funded, multi-person/ multi-partner projects as credibility is established and papers published. Furthermore, research early in the lifecycle of a paradigm may also take place under the auspices of parent disciplines, in our case mobile computing or education studies, before the paradigm establishes its own personnel and departments of in academic institutions. The disparate intellectual backgrounds of the early mobile research learning community certainly influenced how they reasoned about what they were doing, drawing on psychology, education or computing. These factors coloured how 'mobile learning' developed.
This is a largely historical account but current proceedings and journals suggest that this paradigm is stable, static in its research agenda and dwindling in the number of activists.

Latterly, the mobile-specific initiatives merged with educational exploration of other popular digital technologies such as podcasts, micro-blogging and social networks but by this time the national funding environments for innovation and embedding had become bleak. So, we see 'mobile learning' stuck in its early formulations and in its original domains but with a static community and not a lot of big new ideas to reinforce the old ones.

\section{The Emergent Counter-PARADIGM}

We argue that around the time of the arrival of the iPhone - which was symptomatic and symbolic, part cause, part effect - the world of mobile digital technology hit a tipping point, several in fact. This promoted and comprised a growing North American awareness of the affordances and functionality of the smartphone, exemplified by the iPhone; an awareness of the mobile phone in all those foundations, ministries and international agencies staffed by US nationals; a shift in ethos, priorities and preferences in what was becoming known amongst policymakers and officials as the mobile space, specifically around innovation, pedagogy, sustainability and support for education; the emergence of an apps economy and the global economic crisis and the rise of 
neoliberalism, and thus the impact of all of these for the nature and volume of educational research. There were also ongoing global trends in mobile phone technology and systems, namely increased coverage and penetration, increased power, speed, functionality and thus increasingly diverse business models, revenue streams and start-ups.

The more substantial basis for our proposed paradigm is the sheer volume and diversity of web2.0 activity, manifest in traffic on, for example, Facebook, Wikipedia, Twitter, YouTube, Instagram and Pinterest, and the fact that this activity is facilitated by personal mobile technologies and systems. The impact is highly contextual, building from existing local practices, cultures, languages, infrastructure and epistemologies but nevertheless global in extent - a survey of the uses of the missed call (Donner, 2007) illustrates this point.

The nature and volume of this activity and this traffic vastly overwhelm anything that went through any formal education system. We are not endorsing this phenomenon, nor are we saying that it represents 'good' learning, whatever that might mean, we are merely saying it happens. And in doing so, it challenges the epistemological foundations of earlier generations of learning, and thus the paradigm of 'mobile learning' based around the established institutions, professions, pedagogies and curricula no longer have their earlier authority, relevance or significance.

There is a rich and growing literature describing the profound and transformative impact of the widespread ownership of mobile technologies on most aspects of our societies and cultures (Traxler, 2010c). The most obvious is the transformation, at national, organisational and individual levels, of the artefacts, resources, transactions, commodities and assets that constitute economic life and the ways that we, as individuals, organisations and nations, produce, consume and exchange them; these technologies also transform the nature of much work itself by facilitating remote and extended working, out of hours, off the premises, by encroaching on workers' off-duty times and spaces, and by supervising and monitoring and potentially deskilling peripatetic and dispersed workers. Other obvious though minor transformations are in forms of artistic expression, creating or mutating genres for art, creating new artists and new markets for their work, from blogs and flash mobs to ringtones and downloads, and in our political life as the old sedentary institutions and organisations lose touch with the values and concerns of people growing up in a different world; and to crime and wrongdoing initially from BlackBerry-enabled rioting, happy-slapping, blue-jacking and cyber-sex, and then onto trolling and identity-theft. We should however be alert for the numerous moral panics around mobiles (Goggin, 2012).

This short account clearly abbreviates and exaggerates something far more complex and subtle but the points are nevertheless relevant to our discussion. The implications for established education are manifold. Even if the role of education is only to service the economy, the nature of 
that economy is changing rapidly, in ways to which the static institutions of education might be ill suited to monitor. There is of course a wider challenge to educational institutions and that is the challenge of defining a robust and meaningful purpose for education as digital technologies 'hollow out the labour market' (McIntosh, 2013), and thus reduce social mobility and economic opportunity, and defining such a purpose in a world of mass personal digital technology affording connection and mobility.

There are also many accounts of how mobility and connection change how we think of ourselves, our identities, our affiliations, our relationships (Fortunati, 2002) nowadays many people have multiple online identities, sometimes even within the same cyber-space domain and sometimes different genders. These are not merely their real identities and personalities enacted on-line - any more than their avatar in SecondLife is merely a collection of pixels - nor are they somehow less real than the real ones, not a sort of online impersonation or digital fancy-dress but are actually and obviously authentic, locations where emotions and values are established and transformed. The implications for education are the transience, fragmentation and complication of the identities and communities being served, potentially changing the ideas of out-reach and recruitment as individuals reconfigure the places and spaces that they inhabit.

These changes drive changes in expectations about behaviour, about what is good, acceptable, appropriate and okay in our interactions, our relationships, our conversations; our ideas about what is correct, ethical. And what is worth learning and knowing. This happens as mobile technology intrudes more and more into everyday life and as the mobile phone is increasingly the portal to online activities and communities. What defines and characterises communities is a shared consensus about ethics and expectation. What is acceptable as a gesture, a fact, an interaction or a topic in one community is not necessarily so in another, and online communities as opposed to physical communities are much more volatile and tacit - offence is easily given in the wrong place, and newbie educationalists find themselves venturing into the equivalent of foreign countries with strange customs and traditions when they take or they seek students in cyberspace and in phonespace (Townsend, 2000). The mobile phone has become an essential component or presence of every face-toface social and inter-personal interaction, in the café, the conference, the classroom and the concert, the street corner, the bus and the pub, and these interactions change and the rules evolve, quickly or slowly, willingly or unwillingly, consensually or conflictedly. Educators must work with and within a society where the private and social online spaces of music, community and interaction intrude to the physical and self-proclaimed educational spaces and where for example phone calls interrupt conversations, classes and concerts. There is thus a role for professional educators in the world of 'learning with mobiles' but this must focus on empowering criticality 
and judgment not defending static knowledge, positions and expertise.

Joining or creating communities, online or otherwise, means acceding to a set of expectations about how to behave and how to interact; in the online world, these communities are fragmentary, transient and complex, accessible more to those digital resident learners than many of their digital visitor teachers, if we may use such a generalisation (White \& Le Cornu, 2011).

Connected universal mobile devices, the portal onto web2.0 services, also change the nature of learning and knowing. Everyone with a smartphone can generate, store, share, discuss and consume images, ideas, information and opinions, can access the cloud, and the services it provides, and can access each other; they can pursue, sustain or invent interests specific to them, their location, their community and their history.

This sounds like education "but not as we know it" as they say in Star Trek, but an education without the gatekeepers, barriers and constraints of most schools, colleges and universities, and without the support, standards, structure, stability and incentives of these established institutions; these facts are key to our new paradigm of learning with mobiles. The challenge to education systems is of course the shift or discrepancy in control, authority and agency represented not by the technologies themselves but by the social changes around them.

\section{Conclusions}

This article has attempted to explain and conceptualise mobile learning by presenting it as two competing paradigms and using these as the framework for organising experience and evidence. This is clearly a simplification and ignores the various contexts, factors and personalities at work in a complex and evolving fieldwork. It is also a proxy for a wider tension around the nature and purpose of education; our two paradigms are perhaps merely the local instances, focussed on mobile technology, of two over-arching educational paradigms, one about the steady evolution and improvement of the systems that support societies through established institutions, professions and practices, the other about people taking control and responsibility for what they choose to learn and know. The latter might be the true meaning of 'the digital age' but unfortunately much education still takes place in a previous 'digital age'.

\section{References}

Ally, M. (Ed.) (2009). Mobile learning: Transforming the delivery of education and training. AU Press,

Athabasca University.

Arnedillo-Sánchez, I., Sharples, M. \& Vavoula, G. N. (Eds.) (2007). Beyond mobile learning workshop.

Dublin: Trinity College Dublin Press.

Attewell, J., \& Savill-Smith, C. (2004). Learning with mobile devices, London: LSDA.

Attewell, J., Savill-Smith, C., Douch, R., \& Parker, G. (2010). Modernising education and training mobilising technology for learning. London: Learning and Skills Network. 
Becher, T., \& Trowler, P. R. (2001). Academic tribes and territories: intellectual enquiry and the cultures of disciplines. (2nd ed.) Buckingham: Open University Press/SRHE.

Beddall-Hill, N., \& Raper, J. (2010). Mobile devices as 'boundary objects' on field trips. Journal of the Research Center for Educational Technology, 6(1), 28-46.

Botha, A., Vosloo, S., Kuner, J. \& van den Berg, M. (2008). Improving cross-cultural awareness and communication through mobile technologies. In J. Traxler, B. Riordan \& C. Dennett (Eds.), Proceedings of mLearn2008. Telford, UK.

Brown, T. H. (2003). The role of m-learning in the future of e-learning in Africa. $21^{s t} I C D E$ World Conference, Hong Kong, 110, 122-137.

Brown, T. H. (2005). Beyond constructivism: Exploring future learning paradigms. Education Today, 2, 14-30.

Brown, E. (Ed.) (2010). Education in the wild: contextual and location-based mobile learning in action. In F. Fischer, L. Hofmann \& S. Schulz (Eds.), D3.1 A report from the STELLAR Alpine Rendez-Vous workshop series. University of Nottingham: Learning Sciences Research Institute (LSRI).

Brown, T. H., \& Mbati, L. S. (2015). Mobile learning: Moving past the myths and embracing the opportunities. International Review of Research in Open and Distributed Learning. 16(2). 115-135.

Burke, D. (2010). Using mobile devices to enhance fieldwork. In P. Law \& C. Wankel (Eds.), Streaming media in higher education. London, UK: Streaming Media.

Büscher, M., \& Urry, J. (2009). Mobile methods and the empirical. European Journal of Social Theory, 12(1), 99-116.

Chan, T., Roschelle, J., Hsi, S., Kinshuk, Sharples, M., Brown, T., ... \& Hoppe, U. (2006). One-toone technology-enhanced learning: An opportunity for global research collaboration. Research and Practice in Technology Enhanced Learning, 1(1), 3-29.

Collett, M., \& Stead, G. (2002). Meeting the challenge: Producing m-learning materials for young adults with numeracy and literacy needs. In S. Anastopoulou, M. Sharples \& G. Vavoula (Eds.), Proceedings of MLearn 2002, European Workshop on Mobile and Contextual Learning, University of Birmingham, 14, 63-64.

Comas-Quinn, A., Mardomingo, R., \& Valentine, C. (2009). Mobile blogs in language learning: Making the most of informal and situated learning opportunities. ReCALL, 21(1), 96-112.

Corlett, D., \& Sharples, M. (2004). Tablet technology for informal collaboration in Higher Education. In J. Attewell \& C. Savill-Smith (Eds.), Mobile learning anytime everywhere. A book of papers from MLearn 2004 (59-61). Bracciano, Italy.

de Crom, E. P., \& de Jager, A. (2005). The "ME"-learning experience: PDA technology and e-learning in ecotourism at the Tshwane University of Technology. In Proceedings of the MLEARN Conference, Cape Town, South Africa.

Dale, C. (2007). Strategies for using podcasting to support student learning. Journal of Hospitality, Leisure, Sport and Tourism Education, 6(1), 49-57.

Dearnley, C. J., Haigh, J., \& Fairhall, J. (2008). Using mobile technologies for assessment and learning in practice settings: A case study. Nurse Education in Practice, 8(3), 197-204. 
Donner, J. (2007). The rules of beeping: Exchanging messages via intentional "missed calls" on mobile phones. Journal of Computer-Mediated Communication, 13(1), 1-12.

Draper, S. W., \& Brown, M. I. (2004). Increasing interactivity in lectures using an electronic voting system. Journal of Computer Assisted Learning, 20(2), 81-94.

Eaton, B. C. \& Schmitt, N. (1994). Flexible manufacturing and market structure. American Economic Review, 84(4), 875-888.

Engeström, Y. (2001). Expansive learning at work: Toward an activity theoretical reconceptualization. Journal of Education and Work, 14(1), 133-156.

Engeström, Y. (2009). Wildfire activities: New patterns of mobility and learning. International Journal of Mobile and Blended Learning, 1(2), 1-18.

Facer, K., Joiner, R., Stanton, D., Reidt, J., Hull, R., \& Kirk, D. (2004). Savannah: Mobile gaming and learning? Journal of Computer Assisted Learning, 20(6), 399-409.

Fröhberg, D., Göth, C., \& Schwabe, G. (2009). Mobile learning projects - a critical analysis of the state of the art. Journal of Computer Assisted Learning, 25(4), 307-331.

Fortunati, L. (2002). The mobile phone: Towards new categories and social relations. Information, Communication \& Society, 5(4), 513-528.

Gayeski, D. (2002). Learning unplugged. Using mobile technologies for organisational and performance improvement. New York, NY: American Management Association.

Georgiev, T., Georgieva, E., \& Smrikarov, A. (2004). M-learning - a new stage of M-learning. In International Conference on Computer Systems and Technologies - CompSys Tech' 2004, 4(28), 1-4.

Giles, J. (2009). Physios recommend a healthy dose of gaming. London, UK: New Scientist. Retrieved from www.newscientist.com

Goggin, G. (2012). Cell phone culture. Abingdon: Routledge.

Heeks, R. (2008) ICT4D 2.0: The next phase of applying ICT for international development. Computer, 41(6), 26-33. Available at www.nixdell.com

Hlodan, O. (2010). Mobile learning anytime, anywhere. BioScience, 60(9), 682-682.

Holmes, B., \& Gardner, J. (2006). E-learning: concepts and practice. London: SAGE.

Jarvis, C. H., \& Priestnall, G. (2008). Visualisation futures: A teaching and learning perspective. In Horizon Scanning for GIS and Visualisation, Salford, April 1st, 2008.

JISC (2005). Innovative practice with e-learning: A good practice guide to embedding mobile and wireless technologies into everyday practice. Bristol, UK: Joint Information Services Committee.

Kato, P. M., Cole, S. W., Bradlyn, A. S., \& Pollock, B. H. (2008). A video game improves behavioural outcomes in adolescents and young adults with cancer: a randomised trial. Paediatrics, 122(2), 305-317.

Kenny, R. F., Park, C. L., Van Neste-Kenny, J. M. C., Burton, P. A., \& Meiers, P. A. (2009). Using mobile learning to enhance the quality of nursing practice education. In M. Ally (Ed.), Mobile learning: Transforming the delivery of education and training (75-98). Athabasca, AB: Athabasca University Press.

Kneebone, R., \& Brenton, H. (2005). Training perioperative specialist practitioners. In A. KukulskaHulme \& J. Traxler (Eds.), Mobile learning: A handbook for educators and trainers. London: Routledge. 
Koole, M., \& Ally, M. (2006). Framework for the rational analysis of mobile education (FRAME) model: Revising the ABCs of educational practices. In Networking International Conference on Systems and International Conference on Mobile Communications and Learning Technologies (p. 216).

Kuhn, T. S. (1970). The structure of scientific revolutions. Chicago, ILL: University of Chicago Press.

Kukulska-Hulme, A. (2009). Will mobile learning change language learning? ReCALL, 21(2), 157-165.

Kukulska-Hulme, A., Sharples, M., Milrad, M., Arnedillo-Sánchez, I., \& Vavoula, G. (2011). The genesis and development of mobile learning in Europe. In D. Parsons (Ed.), Combining E-Learning and M-Learning: New Applications of Blended Educational Resources (151-177). Hershey, PA: Information Science Reference.

Kukulska-Hulme, A., \& Traxler, J. (Eds.) (2005). Mobile learning: a handbook for educators and trainers. Open and flexible learning series. London: Routledge.

Laurillard, D. (2007). Pedagogic forms of mobile learning: framing research questions. In N. Pachler. Mobile Learning - towards a research agenda (153-177). London: University of London. Available at http://discovery.ucl.ac.uk

Levy, M., \& Kennedy, C. (2005). Learning Italian via mobile SMS. In A. Kukulska-Hulme \& J. Traxler (Eds.), Mobile learning: A handbook for educators and trainers (76-83). Routledge: London.

Lindstrom, L. (1993). Cargo cult: Strange stories of desire from Melanesia and beyond. Honolulu, HI: University of Hawaii Press.

Lonsdale, P., Barber, C., Sharples, M., Byrne, W., Arvanitis, T., Brundell, P., et al. (2004). Context awareness for mobilearn: Creating an engaging learning experience in an art museum. In Proceedings of the World Conference on Mobile Learning, Rome, Italy.

McIntosh, S. (2013). Hollowing out and the future of the labour market. BIS Research Paper, 134.

Metcalf, D. S. (2006). mLearning: Mobile learning and performance in the palm of your hand. Amherst, MA: Human Resource Development Press.

Motlik, S. (2008). Mobile learning in developing nations. The International Review of Research in Open and Distributed Learning, 9(2). Available at https://files.eric.ed.gov

Naismith, L., \& Corlett, D. (2006). Reflections on success: A retrospective of the mLearn conference series 2002-2005. In mLearn 2006: Across generations and cultures, Banff, Canada.

Naismith, L., Lonsdale, P., Vavoula, G., \& Sharples, M. (2005). Report 11: Literature Review in Mobile Technologies and Learning. Bristol: NESTA Futurelab. Available at www2.futurelab. org.uk

Nikoi, S. (2007). Literature Review on Work-Based Mobile Learning, Work-based Learners in Further education (WoLF) project. Available at http://wolf.lec.ac.uk

Peters, O., \& Keegan, D. (1994). Otto Peters on distance education: the industrialization of teaching and learning. London : Routledge.

Pfeiffer, V. D. I., Gemballa, S., Jarodzka, H., Scheiter, K., \& Gerjets, P. (2009). Situated learning in the mobile age: Mobile devices on a field trip to the sea. International Journal of Research in Learning Technology, 17(3), 187-199. 
Pulman, A. (2008). Mobile assistance - the Nintendo DS Lite as an assistive tool for health and social care students. Available at http://www.swap.ac.uk

Quinn, C. (2012). mLearning: mobile, wireless, in your pocket learning. LineZine, Fall.

Rainger, P. (2005). Accessibility and mobile learning. In A. Kukulska-Hulme \& J. Traxler (Eds.), Mobile learning: A handbook for educators and trainers. London: Routledge.

Riordan, B., \& Traxler, J. (2005). The use of targeted bulk SMS texting to enhance student support, inclusion and retention. In WMTE, IEEE, Japan, November.

Rogers, E. M. (2010). Diffusion of innovations. (4th ed.). New York: Simon and Schuster.

Sharples, M. (Ed.). (2006). Big issues in mobile learning. University of Nottingham, UK: Kaleidoscope Network of Excellence.

Sharples, M., Taylor, J., \& Vavoula, G. (2007). A theory of learning for the mobile age. In R. Andrews $\&$ C. Haythornthwaite (Eds.), The Sage handbook of elearning research (221-247). London: Sage.

Shih, Y. E. (2007). Setting the new standard with mobile computing in online learning. The International Review of Research in Open and Distributed Learning, 8(2).

Smith, C. (2008). Simulation as an aid to archaeological drawing. In Teaching and Learning in Archaeology 2008 Conference, University of Liverpool, June 25th-26th, 2008.

Smördal, O., \& Gregory, J. (2003). Personal Digital Assistants in medical education and practice. Journal of Computer Assisted Learning, 19(3), 320-329.

Teichler, U. (1998). Massification: A challenge for institutions of higher education. Tertiary Education and Management, 4(1), 17-27.

Thornton, P., \& Houser, C. (2005). Using mobile phones in English education in Japan. Journal of Computer Assisted Learning, 21, 217-228.

Townsend, A. M. (2000). Life in the real-time city: Mobile telephones and urban metabolism. Journal of Urban Technology, 7(2), 85-104.

Traxler, J. (2005). Defining mobile learning. In IADIS International Conference Mobile Learning (261-266).

Traxler, J. (2008a). Learning in a mobile age. International Journal of Mobile and Blended Learning, $1(1), 1-12$.

Traxler, J. (2008b). Mobile learning in a mobile world. The practicalities of the social, ethical and legal environment. In T. Hansson (Ed.). Handbook of research on digital information technologies: Innovations, methods, and ethical issues. Hershey, PA: Information Science Reference.

Traxler, J. (2010a). e-Learning - the next wave. In A. Jeffries (Ed.), Proceedings of ALT-C, Association for Learning Technology, Oxford. Available at http://repository.alt.ac.uk

Traxler, J. (2010b). Students and mobile devices. Research in Learning Technology, 18(2), 149-160.

Traxler, J. (2010c). The 'learner experience' of mobiles, mobility and connectedness. An interpretative literature review for HEA ELESIG. Available at http://citeseerx.ist.psu.edu

Traxler, J. (2015). Digital life, mobile learning and the arab spring of education. GLOKALde, 1(3), $12-20$.

Traxler, J. (2016) Inclusion in an age of mobility. Research in Learning Technology, 24. 
Traxler, J., \& Griffiths, L. (2009). IWB4D - interactive whiteboards for development. In Proceedings of the International Conference on Information and Communication Technologies and Development (488). Doha, Qatar.

Traxler, J., \& Kukulska-Hulme, A. (Eds.) (2015). Mobile learning: The next generation. New York: Routledge.

Traxler, J., \& Leach, J. (2006). Innovative and sustainable mobile learning in Africa. In Wireless, mobile and ubiquitous technology in education (98-102). WMUTE'06. Fourth IEEE International Workshop.

Unterfrauner, E., Marschalek, I., \& Fabian, C. M. (2010). Mobile learning with marginalized young people. In I. Arnedillo Sánchez \& P. Isaias (Eds.), Proceedings of the IADIS International Conference Mobile Learning (28-35).

Vavoula, G. N., Lefrere, P., O’Malley, C., Sharples, M., \& Taylor, J. (2004). Producing guidelines for learning, teaching and tutoring in a mobile environment. In J. Roschelle, T. Chan, Kinshuk \& S. J. H. Yand (Eds.), Proceedings of the 2nd IEEE International Workshop on Wireless and Mobile Technologies in Education (173-176). Los Alamitos, CA: Computer Society Press.

Wagner, E. D. (2005). Enabling mobile learning. EDUCAUSE Review, 40(3), 41-42.

Walsh, C. S., Shrestha, P., \& Hedges, C. (2011). Leveraging low-cost mobile technologies in Bangladesh: A case study of innovative practices for teacher professional development and communicative English language teaching. In R. Kwan et al. (Eds.), Enhancing learning through technology. Education unplugged: Mobile technologies and web 2.0 (151-166). Berlin: Springer.

White, A., Allen, P., Goodwin, L., Breckinridge, D., Dowell, J., \& Garvy, R. (2005). Infusing PDA technology into nursing education. Nurse Educator, 30(4), 150-154.

White, D. S., \& Le Cornu, A. (2011). Visitors and residents: A new typology for online engagement. First Monday, 16(9).

Winters, N. (2006). What is mobile learning? In M. Sharples (Ed.), Big issues in mobile learning (6-9). Nottingham: Kaleidoscope Network of Excellence.

Worsley, P. (1957). The trumpet shall sound: a study of "cargo" cults in Melanesia. London: MacGibbon \& Kee.

Yau, J. Y-K., \& Joy, M. (2009). Context-aware and adaptive learning schedule for mobile learning. In Proceedings of the mobile and ubiquitous learning workshop (512-519). 17th International Conference on Computers in Education (ICCE 2009). Available at http://ftp.dcs.warwick.ac.uk

John Traxler (United Kingdom), University of Wolverhampton, Institute of Education; e-mail:john.traxler@wlv.ac.uk 